\title{
On the electrokinetic characterization of charged polymeric membranes by transversal streaming potential
}

\author{
V. M. Barragán*a, J. P. G. Villaluenga a , M.A. Izquierdo-Gil a , K. R. Kristiansen b \\ (a) Department of Structure of Matter, Thermal Physics and Electronics, Complutense \\ University of Madrid, 28040 Madrid, Spain. \\ (b) PoreLab, Department of Chemistry, Norwegian University of Science and Technology, \\ N-7491, Trondheim, Norway \\ (*) Corresponding author. Tel (+34) 913945094; e-mail: vmabarra@ucm.es
}

\begin{abstract}
The effect of a transmembrane pressure on the electrokinetic properties of different polymeric charged membranes is analyzed. Electrokinetic characterization can involve the application of increasing or decreasing pressure differences over a membrane sample. The aim of this work is to study whether the transmembrane pressure application during the measurement process to determine the zeta potential and the intrinsic permeability of polymeric membranes causes a membrane irreversible change. It is a relevant issue in membrane technology, because electrokinetic properties are used to analyze the viability and performance of ion-exchange membranes processes in practical applications. We show that polymeric membranes can be affected by a transmembrane pressure application. This influence does not affect surface charge distribution of the polymeric membranes, but it can strongly affect the membrane structure.
\end{abstract}

Keywords: Charged polymeric membranes; Irreversible change; Streaming potential; Hydraulic permeability; Electrokinetic phenomena 


\section{Introduction}

Streaming potential is the voltage difference between upstream and downstream of liquid flow at zero electric current due to a pressure gradient through a charged capillary, and it is caused by a charge accumulation originated by the flow of part of charges in the diffuse layer. From streaming potential, zeta potential, defined at the shear plane, can be estimated, being considered an useful representation of the potential at the charged surface [1]. Thus, streaming potential is a common widely used experimental technique for electrokinetic characterization of a charged solid-electrolyte interface [2-16]. Electrostatic interactions between ions in the water and the membrane surface charge play an important role in ion separation based on Donnan exclusion [17-19]. Moreover, the electrochemical properties of a membrane surface and the macromolecules presented in solution may have a significant influence on the nature and magnitude of the membrane-solute interactions. For this reason, preventing fouling in different technologies using charged membranes, such as nanofiltration, reverse osmosis, reverse electrodialysis, or multistage flash distillation, has become a major research focus [20-25], and streaming potential measurements have been used to investigate the surface characteristics of ultrafiltration membranes, and to determine the interactions between the foulant and the membrane $[3,26]$ or for characterizing ion-exchange membranes used in electrodialysis [27]. The fouling of membranes by biological macromolecules such as proteins is also dependent on the zeta potential of the membranes and the protein charge [28]. Accurate estimating membrane zeta potential is critical for interpreting membrane fouling propensity and the transport phenomena of charged contaminants in the presence of brackish and saline feed streams [11]. Characterizing the streaming potential has been shown essential in applying seismoelectric and electroseismic phenomena for oil exploration using polymeric materials for electro-osmosis micropumps [8], for characterizing porous 
transducer [12], to predict the performance of nanofiltration membranes [29], or for on-line control of polymer dosage for waterworks sludge conditioning [30].

Fluid flow and charge transport are closely interrelated due to the formation of the electrochemical double layers on the solid-liquid interfaces. Thus, another important aspect to consider is the transport of liquid, which may arise from the pressure difference stablished between the both sides of the membrane. In pressure-driven processes, this flow is a key aspect of the process performance. The hydraulic permeability is a parameter that characterizes the productivity of a membrane in a pressure-driven membrane process. This parameter refers to the resistance of a solid matrix due to pressure driven flux, and it is usually estimated from the permeate flux as a linear function of the applied pressure in agreement with the Darcy's law [31-34]. Moreover, a pressure difference can also appear between both sides of the membrane in several electromembrane-processes involved in energy generation processes, such as polymer electrolyte fuel cells [35] or reverse electrodialysis [36]. The hydraulic permeability is a crucial parameter in electrokinetic energy conversion because it negatively affects the figure-of-merit of the conversion process and, thus, affects the energy conversion efficiency [37-39]. Hydraulic permeability can also be estimated from the time dependence of the transversal streaming potential, when it is measured by flowing liquid through the membrane [40]. In this case, measurements usually involve the application of increasing or decreasing pressure difference over a membrane sample, and streaming potential and hydraulic permeability can be calculated from the linear relation between the voltage difference across the membrane and the applied transmembrane pressure difference.

Most of the commercial membranes used in pressure-driven application possess a polymeric matrix. In addition, ion-exchange resins used in electromembrane-processes are often polymers that carry fixed functional groups. The viability and performance of ion- 
exchange membranes processes in practical applications are dependent on membrane properties. In particular, the mechanical properties of thin polymeric membranes are of wide interest to control processes because they affect the durability and lifetime, both related to the polymer degradation $[41,42]$. There is evidence that polymeric membranes can be affected by the application of a transmembrane pressure [43-46] originating polymer degradation. Thus, it is a very important issue in characterization techniques involving the application of a transmembrane pressure to know its effect on the membrane properties. In this context, we discuss the influence of the transmembrane pressure application on both transversal streaming potential and hydraulic permeability measurements in typical charged polymeric membranes.

\section{Theoretical fundamentals}

According to the linear irreversible thermodynamics approach $[47,48]$, the flux-force equations for an isothermal membrane system can be written as:

$$
\begin{aligned}
& J_{e}=-L_{e e} \nabla \mu_{e}-L_{e w} \nabla \mu_{w}-L_{e \psi} \nabla \psi \\
& J_{w}=-L_{w e} \nabla \mu_{e}-L_{w w} \nabla \mu_{w}-L_{w \psi} \nabla \psi \\
& J=-L_{\psi e} \nabla \mu_{e}-L_{\psi w} \nabla \mu_{w}-L_{\psi \psi} \nabla \psi
\end{aligned}
$$

where $J_{e}, J_{w}$ and $J$ are, respectively, electrolyte, water and charge fluxes, $\nabla \mu_{e}$ and $\nabla \mu_{w}$ electrolyte and water chemical potential gradients, respectively, and $\nabla \psi$ the electric potential gradient. The coefficients $L_{\mathrm{ij}}$ are the phenomenological coefficients.

If reversible $\mathrm{Ag} / \mathrm{AgCl}$ electrodes are used, the isothermal cell is represented as:

$$
\operatorname{Ag}(\mathrm{s})|\operatorname{AgCl}(\mathrm{s})| \operatorname{KCl}\left(c_{0}\right) \mid \text { ion-exchange membrane }\left|\operatorname{KCl}\left(c_{0}\right)\right| \operatorname{AgCl}(\mathrm{s}) \mid \operatorname{Ag}(\mathrm{s})
$$

where the electrolyte concentration, $c_{0}$, is identical on both sides of the membrane. When a transmembrane pressure is stablished between them, an electric potential difference, $\Delta \psi 0$, is originated. With any concentration difference stablished between two sides of the membrane, the chemical potential gradient has only the pressure dependent contribution, $V_{\mathrm{i}} \nabla p$, with $V_{\mathrm{i}}$ 
the partial molar volume of component $i$ and $p$ the hydrostatic pressure. In this case, the streaming potential difference is the open-circuit voltage $\Delta \psi 0$, which is obtained from the third expression in Eq. (1) by setting $J=0$ as follows

$$
\beta_{0} \equiv\left(\frac{\Delta \psi_{0}}{\Delta p}\right)_{J=0}=-\frac{L_{\psi e} V_{e}+L_{\psi w} V_{w}}{L_{\psi \psi}}
$$

where the pressure coefficient, $\beta_{0}$, is defined in absence of electric current. To obtain the true value of the streaming potential, $\Delta \psi r$, the electrode contribution must be subtracted from $\Delta \psi_{0}:$

$$
\Delta \psi_{r}=\Delta \psi_{0}-\frac{1}{F}\left(\bar{V}_{A g C l}-\bar{V}_{A g}\right) \Delta p
$$

where $F$ is the Faraday's constant, and $\bar{V}_{A g C l}$ and $\bar{V}_{A g}$ are the molar volumes of $\mathrm{AgCl}$ and Ag, respectively [49].

Thus, the true value of the pressure coefficient, $\beta_{\mathrm{r}}$, can be estimated by

$$
\beta_{r}=\left(\frac{\Delta \psi_{r}}{\Delta p}\right)_{J=0}=\beta_{0}-\frac{1}{F}\left(\bar{V}_{A g C l}-\bar{V}_{A g}\right)
$$

If the pressure coefficient is known, the electro-osmotic drag coefficient, $k_{w}$, can be determined for each membrane system as follows [50]:

$$
k_{w}=\frac{F W \rho}{M}
$$

where $\rho$ and $M$, are the density and the molecular mass of the transported flow, respectively, and $W$ is the electro-osmotic permeability. The electro-osmotic permeability is, according to the Onsager relations [51], equal to the pressure coefficient. This coefficient quantifies how many water molecules are carried along with each counter-ion at the vectored counter-ion transport path through the membrane, assuming the gradient of the water concentration negligible through the whole membrane. 
The formation of an electrical double layer occurs when a solid surface featuring electrical charges is in contact with a liquid that contains mobile charges. The electrical potential at the shear plane is defined as the zeta potential, $\zeta$. From the pressure coefficient value, the zeta potential can be estimated using the Helmholtz-Smoluchowski equation $[11,52]$ :

$$
\beta_{r}=\frac{\varepsilon_{0} \varepsilon_{r} \zeta}{\eta \kappa}
$$

where $\varepsilon_{0}$ is the vacuum permittivity and $\varepsilon_{r}, \kappa$ and $\eta$ are, respectively, the relative dielectric constant, electric conductivity and dynamic viscosity of the solution. The zeta potential indicates the electrical potential at the plane of shear between the stationary and mobile parts of the electric double layer at the membrane-solution interface. It is noted that the HelmholtzSmoluchowski equation is valid for electrolyte solutions with ionic strengths greater than $0.001 \mathrm{M}[20]$.

In fact, the solutions at both sides of the membranes are identical only in the start of the experiments, at time equal to zero. Later, during the process, a concentration difference arises between both sides of the membrane. The contribution of the concentration polarization is usually eliminated by determining the streaming potential as an intercept at time zero, $\Delta \psi_{0}$, from the plot of the electrical potential difference versus $t^{1 / 2}[53,54]$ :

$$
\Delta \psi=\Delta \psi_{0}-A \sqrt{t}
$$

where $\Delta \psi_{0}$ is the electric potential difference in the absence of concentration polarization. As there is no liquid flow through the membrane at this stage, the parameter $A$ can be related to the hydraulic permeability, $L_{p}$, in the membrane as follows

$$
L_{p}=\frac{A}{f \Delta p}
$$

where $\Delta p$ is the transmembrane pressure, and $f$ is given by: 


$$
f= \pm \frac{8 R T}{F} t_{i} \sqrt{\frac{1}{\pi D_{K C l}}}
$$

where sign + or - is applied, respectively, for cation or anion membranes, $t_{i}$ is the corresponding co-ion transport number in free solution, and $D_{\mathrm{KCl}}$ is the diffusion coefficient of $\mathrm{KCl}$. Thus, it is possible to estimate the hydraulic permeability from the dependence of the electromotive force with time in the isothermal cell shown in (2).

It is worth noticing that several assumptions are implicit in Eq. (10). Thus, activity coefficients are considered constant; at low concentrations, water transference is much smaller than unity and may be considered negligible; and perfectly selective membranes are considered. Since the second law demands that $L_{p}$ must be positive, we expect that $A$ must be also positive for cation membranes and negative for anion membranes, which is in agreement with our results.

The viscosity and the density of the permeant used in hydraulic permeability testing influence on the results, and thus $L_{\mathrm{p}}$ depends on both liquid and medium. The contribution of the medium is given by the intrinsic permeability, $K$, expressed as $[55,56]$ :

$$
K=L_{p} \eta d
$$

where $d$ indicates the membrane thickness.

\section{Experimental}

Two homogenous and two heterogeneous commercial charged polymeric membranes have been used in this work. The homogenous membranes were two Neosepta membranes, the cation-exchange membrane Neosepta CMX (hereinafter CMX) and the anion-exchange membrane Neosepta AMX (hereinafter AMX). CMX cation membranes are composites prepared on the base of polystyrene and divinylbenzene, and reinforced with polyvinylchloride. The ionic fixed sites are sulfonic acid groups. AMX anion membranes 
are composed of styrene divinylbenzene copolymers with tri-alkyl ammonium fixed charge groups. They contain a reinforcing inert mesh. The heterogeneous membranes were two Ralex membranes, the Ralex CM(H)-PES cation-exchange membrane (hereinafter RXC) and the Ralex $\mathrm{AM}(\mathrm{H})$-PES anion-exchange membrane (hereinafter RXA). They are composites formed from ion-exchange resins with polyethylene basic binder and the reinforcing material is a polyester fitting fabric. The ion-exchange group is a sulfonic group for RXC membranes and a quaternary ammonium group for RXA membranes. The selected membranes are suitable for application in electromembrane processes like electrodialysis, electrodeionization or electrophoresis, among others. Relevant characteristics for these membranes are given in Table 1.

\section{Table 1}

Ion exchange capacity (IEC), density, thickness, and liquid uptake of ion-exchange membranes used in this study.

\begin{tabular}{|l|c|c|c|c|}
\hline Membrane & RXA & RXC & AMX & CMX \\
\hline IEC $\left(\mathrm{meq} \cdot \mathrm{g}^{-1}\right)^{*}$ & 1.8 & 2.2 & 1.3 & 1.7 \\
\hline Density $\left(\mathrm{kg} \cdot \mathrm{m}^{-3}\right)^{* *}$ & 945 & 817 & 1090 & 1000 \\
\hline Dry thickness $\left(10^{-6} \mathrm{~m}\right)^{* *}$ & $454 \pm 15$ & $431 \pm 13$ & $129.0 \pm 1.7$ & $151.0 \pm 2.8$ \\
\hline Wet thickness $\left(10^{-6} \mathrm{~m}\right)^{* * *}$ & $750 \pm 10$ & $735 \pm 10$ & $140 \pm 5$ & $173 \pm 5$ \\
\hline Water uptake $(\%)^{* *}$ & 56.0 & 64.5 & 21.0 & 30.0 \\
\hline Liquid uptake $(\%)^{* * *}$ & 51.9 & 56.1 & 20.9 & 23.9 \\
\hline
\end{tabular}

* Given by the manufacturer

*** Measured

${ }^{* * * *}$ Measured in $\mathrm{KCl} 0.01$

Liquid uptake by the membranes was estimated by using the usual gravimetric method [57] at $25.0 \pm 0.1^{\circ} \mathrm{C}$. Membranes thickness was measured with a PCE-THM-20 material thickness meter with resolution $0.0002 \mathrm{~mm}$. Final value of membrane thickness was obtained by averaging the results of at least ten measurements made at different points of the sample under study. Aqueous $\mathrm{KCl}$ solutions of $0.01 \mathrm{M}$ concentration were used as electrolyte.

Figure 1 shows SEM (scanning electron microscope) images of the new unused membranes samples used in this work. Figures 1(a) and 1(b) correspond to heterogeneous 
RXA and RXC membranes and homogeneous AMX and CMX membranes, respectively.

The images show important surface morphological differences between the different membrane samples.
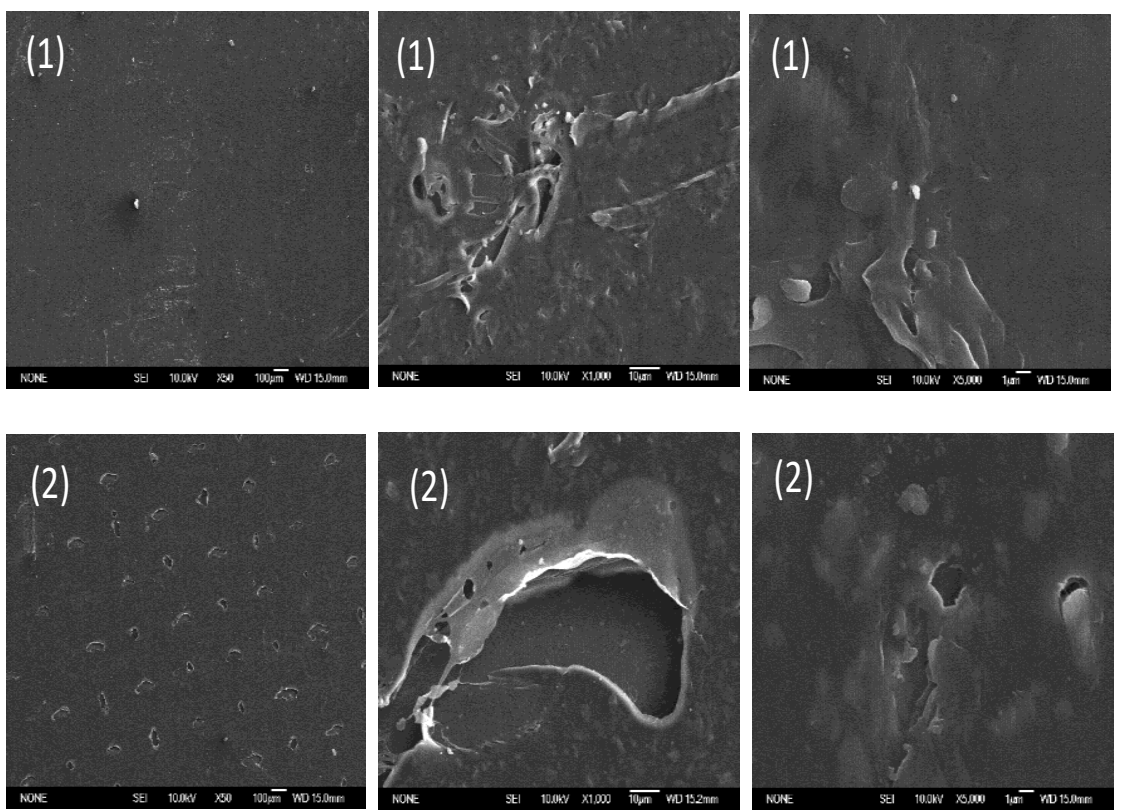

(a)
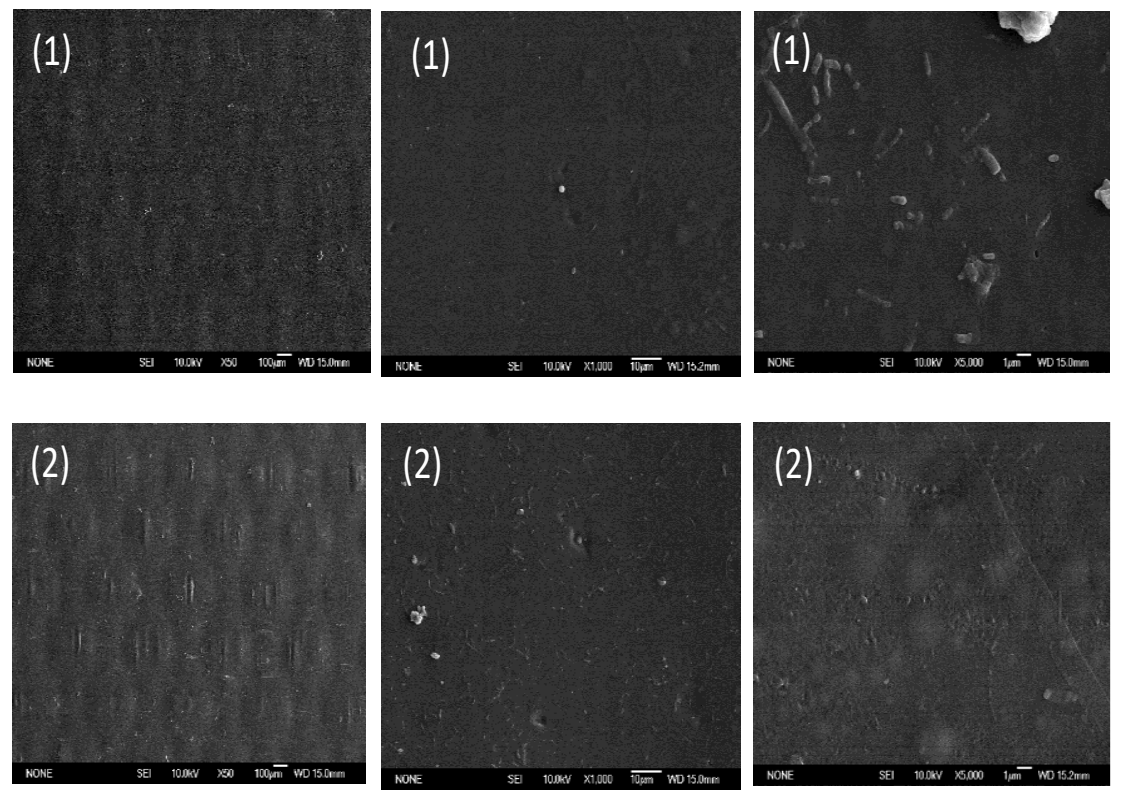

(b)

Fig. 1. SEM images of the membranes used in this work (Spanish National Centre for Electron Microscopy ICTS). (a) Heterogeneous membranes: (1) RXA; (2) RXC; (b) Homogeneous membranes: (1) AMX; (2) CMX 
The experimental device and the procedures used in this study were essentially the same as those described in [5]. $\mathrm{Ag} / \mathrm{AgCl}$ electrodes were used to measure the electric potential difference with the electrode immersed in the lower pressure solution permanently grounded. The pressure pulses were generated with pure pressurized air through a double pressure reducer. Pulses up to 1 bar were applied. The low pressure half-cell was always kept at atmospheric pressure. The pressure difference was measured with a digital manometer with $68.9 \mathrm{~Pa}(0.01 \mathrm{psig})$ resolution. The whole cell was immersed in a thermostatic bath at 25.0 $\pm 0.1^{\circ} \mathrm{C}$. Before experiments, each membrane sample was immersed in aqueous $0.01 \mathrm{M} \mathrm{KCl}$ solution for a minimum of 48 hours in order to achieve equilibrium.

\section{Results and discussion}

\subsection{Measurements with new unused membrane samples.}

The electric potential difference that appeared when a pressure difference around 1 bar was established between both sides of a membrane was measured as a function of time. Results in Figure 2a show the typical behaviour exhibited by a set of new unused membrane samples. In general, the curves were qualitatively similar in all cases. When the pressure difference was applied, the electric potential increased significantly within a few seconds, followed by a slower increase. Later, when the pressure difference across the membrane was removed, the potential difference decreased abruptly within a few seconds, followed by a decrease to a constant value. As it's expected, negative values of the electric current were found for cation-exchange membranes, and positive values for anion-exchange membranes [58].

It has been reported elsewhere [45] that after applying a transmembrane pressure over polymeric membranes, an instantaneous pressure drop occurred, and afterward the pressure difference decreased for a few seconds until a stationary value was reached. This behaviour was attributed to the viscoelastic deformation of the membranes. In the present study, we 
found that the pressure drop was lower than 0.03 bar in the most unfavourable case, and a stationary value was reached in a few seconds.

Corresponding lines showing the electric potential difference versus $t^{1 / 2}$ used to determine the streaming potential ( $\left.\Delta \psi_{0}\right)$ according to Eq. (8) are plotted in Figure $2 \mathrm{~b}$. The initial time interval to perform the linear regressions was chosen testing different points as initial time, and choosing those which gave a correlation coefficient closer to unity [59]. However, we found that the experimental curves $\Delta \psi-t$ exhibited a deviation from the expected linear relationship. Here, this nonlinear behaviour is related to the membrane deformation during operation [45], [60]. In these cases, to perform the correlation analysis, we fitted our data in two time intervals. We consider that the first time interval (named transitory interval) ranges from the initial time to the time where deviation from the linear regression appears (as a rule, we consider as the last time those for which the regression coefficient was higher than 0.99). Whereas, a second interval (named stationary interval) ranges from the last measured time to the time where the second linear fits gave a correlation coefficient closer to unity (as a rule, we consider as the first time those for which the regression coefficient was higher than 0.99). These times depend on the membrane and the pressure difference, but in general, the final time for short $t$ was around 40-60 $\mathrm{s}$ and long $t$ corresponds to times higher than $100 \mathrm{~s}$. Nevertheless, it should be noted that the selection of the time interval to fit experimental data to Eq. (8) can affect significantly the values of the estimated parameters $\Delta \psi_{0}$ and $A$.

Figures $2 \mathrm{c}$ and $2 \mathrm{~d}$ show, respectively, the values of $\Delta \psi_{0}$ and $A$ estimated using the whole time interval (denoted all $t$ ), the initial transitory interval (denoted short $t$ ), and the stationary interval (denoted long $t$ ). Comparing to the experimental values shown in curves $\Delta \psi$ - $t$, we found that the values of $\Delta \psi_{0}$ were overestimated when all $t$ or long $t$ intervals were used. In addition, the values of the parameter $A$ depended on the time interval used in the calculations. 
Thus, larger values were obtained in the short $t$ interval than in the long $t$ interval. Using these values in combination with Eqs. (4-6, 8-10), we estimated the pressure coefficient (at short $t$ ), the transient hydraulic permeability, and the stationary hydraulic permeability. See Table 2.
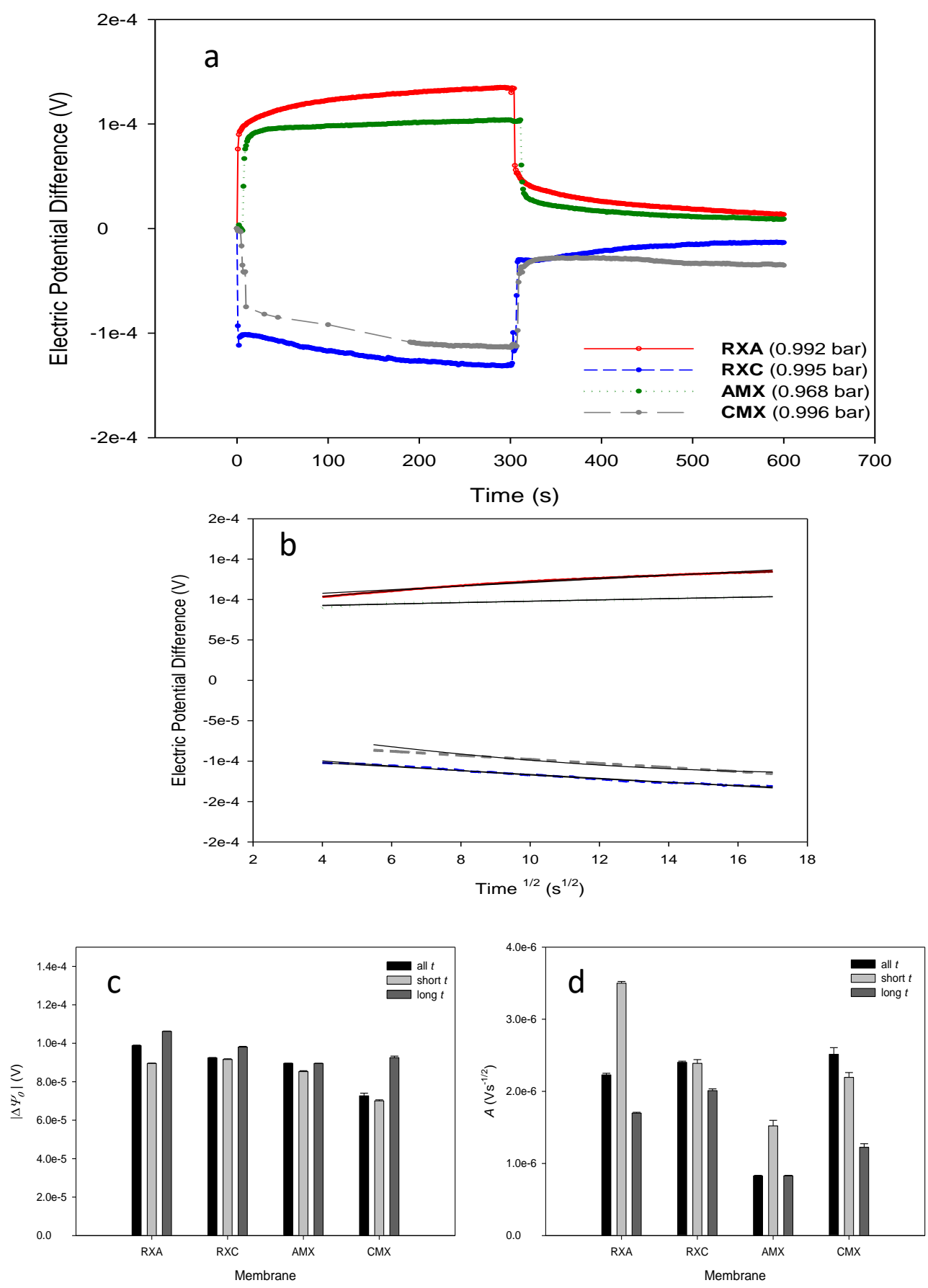

Fig. 2. a) Electric potential difference originated by the indicated pressure difference across the new unused membrane sample as a function of time. b) Corresponding lines showing the 
electric potential difference $v s$. time square root. c) Streaming potential obtained from fitting $\Delta \psi$ vs. $t$ data to Eq. (8); d) Parameter $A$ obtained from fitting $\Delta \psi v s . t$ data to Eq. (8).

\section{Table 2}

True pressure coefficient (estimated at short $t$ ), $\beta_{r, \text { new }}$, electro-osmotic drag coefficient, $k_{w, \text { new }}$, and hydraulic permeability estimated from transitory, $L_{p}{ }^{\text {tran }}{ }_{\text {, new }}$, and stationary, $L_{p}{ }^{\text {stat }}{ }_{\text {, new }}$, intervals, using new membrane samples.

\begin{tabular}{|l|c|c|c|c|}
\hline Membrane & $\begin{array}{c}\boldsymbol{\beta}_{r, \text { new }} \\
\left(10^{-10} \mathrm{~V} \cdot \mathrm{Pa}^{-1}\right)\end{array}$ & $\boldsymbol{k}_{\boldsymbol{w}, \text { new }}$ & $\begin{array}{c}\boldsymbol{L}_{\mathbf{p}}^{\text {tran }}{ }_{\text {, }} \text { ew } \\
\left(10^{-14} \mathrm{~m}^{-1} \mathrm{~s}^{-1} \cdot \mathrm{Pa}^{-1}\right)\end{array}$ & $\begin{array}{c}\boldsymbol{L}_{\mathbf{p}}{ }^{\text {stat }},{ }^{\text {new }} \\
\left(10^{-14} \mathrm{~m}^{-1} \mathrm{~s}^{-1} \cdot \mathrm{Pa}^{-1}\right)\end{array}$ \\
\hline RXA & $7.45 \pm 0.03$ & 4 & $2.71 \pm 0.13$ & $1.32 \pm 0.09$ \\
\hline RXC & $-10.78 \pm 0.02$ & 6 & $1.85 \pm 0.10$ & $1.50 \pm 0.08$ \\
\hline AMX & $7.24 \pm 0.01$ & 4 & $1.21 \pm 0.08$ & $0.65 \pm 0.04$ \\
\hline CMX & $-8.61 \pm 0.14$ & 5 & $1.63 \pm 0.08$ & $0.91 \pm 0.09$ \\
\hline
\end{tabular}

The values of the pressure coefficient shown in Table 2, estimated at short $t$, were in agreement with the values found in the literature for similar membranes $[2,3,6,8,10,53,54]$. The results seem to indicate that, due to the time dependence of the hydraulic flow, short $t$ sequence is more appropriate to determine $\Delta \psi_{0}$ from Eq. (8).

Values obtained for the electro-osmotic drag coefficient agree with typical values for polymer electrolyte membranes obtained using different methods [61-65]. Higher values of the pressure coefficient and thus, of the electro-osmotic drag coefficient, were obtained for cationic membranes, which presented values more different from each other than the anionic membranes. These results are in agreement with the results found by Wang et al. [61], Jacobson et al. [62] and García-Nieto and Barragán [63]. In these studies, lower water electro-osmotic drag coefficients were found for anion-exchange membranes in comparison with cation-exchange membranes. In homogeneous membranes, the higher the swelling, the higher the electro-osmotic transport. This can be due to an increase of the channel diameters in the membrane, and that the ions can be carried along in the solvating envelope more easily $[5,59,66]$. Morevover, electroomotic transport depends on the counter-ion hydration, and anions possesses, in general, lower hydration shell that cations [67]. The results presented in this study are in agreement with this idea. 
The hydraulic permeability of the membranes was estimated from parameter $A$, using Eqs. (8-10). The order of magnitude agreed with the results found in the literature $[53,68]$ for similar systems, and they were similar than the previously obtained with $\mathrm{NaCl}$ solutions with RXC and CMX cation-exchange membranes [10]. Heterogeneous Ralex membranes showed larger hydraulic permeability values than homogenous Neosepta membranes, with higher density.

Here, we found that the membranes exhibited the largest volume flux at the first stage of the process. We consider that this fact may be related to the viscoelastic properties of the membranes [69]. The membranes are deformed under the application of a transmembrane pressure over them, increasing their area [45], and decreasing their thickness. Zich and Václavíková [70] reported both volume and thickness changes in anion and cation exchanges membranes under the action of a hydrostatic pressure difference across them. Moreover, they found that the observed changes were larger for anion-exchange membranes than for cation-exchange membranes. Both, area increase and thickness decrease would lead to a higher volume flux. This change would occur at the beginning of the process until stationary values for area and thickness were reached. It would explain why parameter $A$ in Eq. (8) was not constant in the time.

\subsection{Measurements with used membrane samples.}

Measurements were also carried out applying several pressure difference values between 0 and $10^{5} \mathrm{~Pa}$ with $0.01 \mathrm{M} \mathrm{KCl}$ aqueous solutions to the same membrane sample. To verify the existence of hysteresis, the measurements were performed, using the same sample in the measurements, in two different sequences. In the first one, called "downward pressure", the applied pressure difference was gradually decreased, starting the first measurement with the highest pressure value. In the second one, called "upward pressure", the applied pressure 
difference was gradually increased from the lowest to the highest starting value. The results obtained are shown in Figs. $3 \mathrm{a}$ and $3 \mathrm{~b}$ for heterogeneous and homogeneous membranes, respectively. Continuous and dashed lines correspond, respectively, to the results obtained with the downward and upward pressure sequences. They were in agreement with the expected behaviour, with an increase/decrease of the electric potential difference with increasing/decreasing the applied pressure difference.
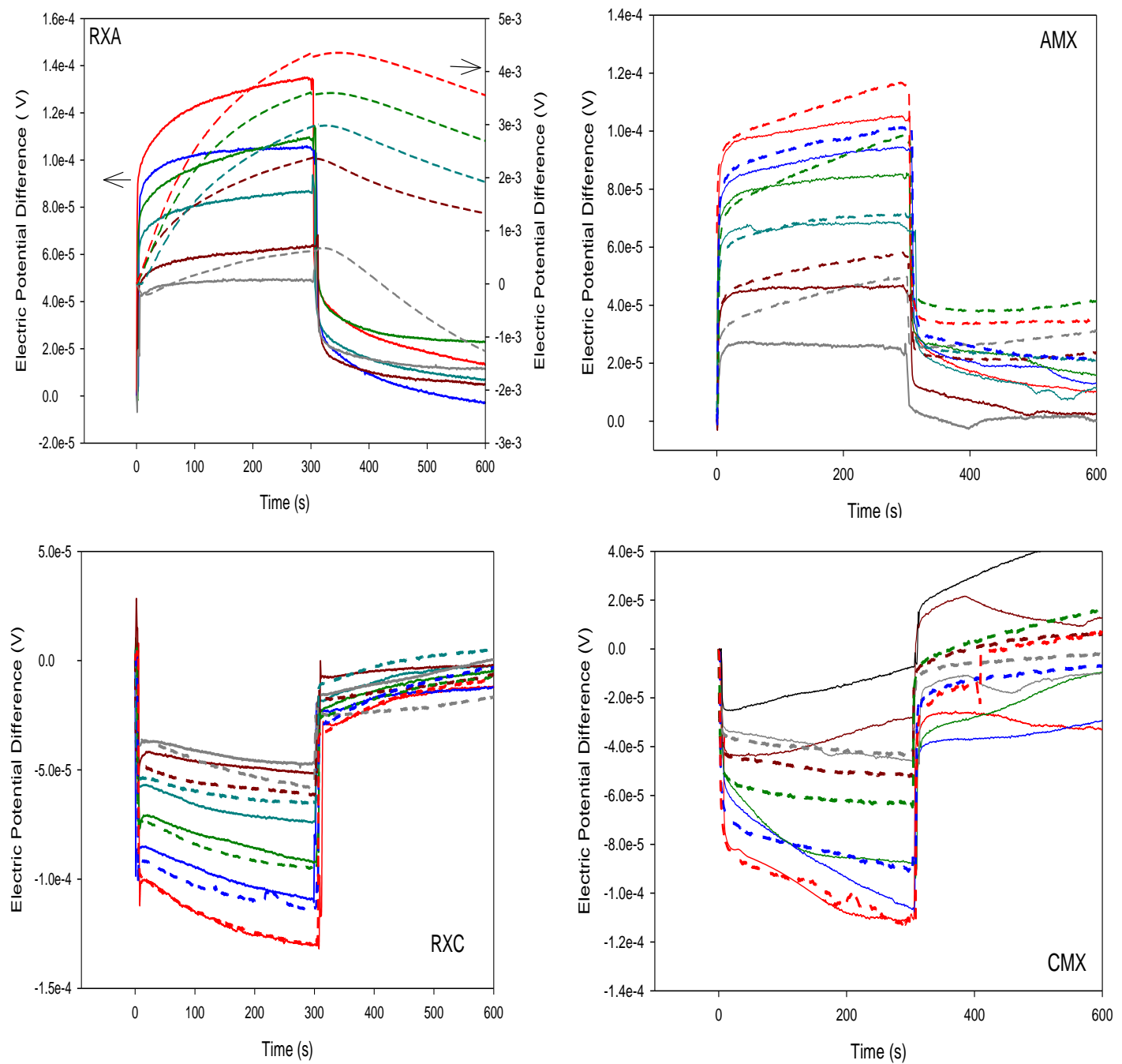

(a)

(b)

Fig. 3. Electric potential difference originated by several pressure differences across the membrane as a function of time (a) Heterogeneous RXA (top) and RXC (bottom) membranes; (b) Homogeneous AMX (top) and CMX (bottom) membranes. Red colour corresponds to the highest value of the applied pressure difference and grey colour to the lowest value. Continuous and dashed lines correspond, respectively, to downward and upward pressures sequences. 
In general, the curves were qualitatively similar in all cases, with the exception of the results obtained for the anionic RXA membranes with the upward pressure sequence. In this case, the sudden increase and decrease, when the pressure difference was first applied and after removed, were not observed. Moreover, the variation of the electric potential with time did not follow the general trend exhibited by the other membranes.

Corresponding lines showing the electric potential difference versus $t^{1 / 2}$ were determined in all the cases. Figure 4 shows, as an example, the results obtained for AMX membrane.
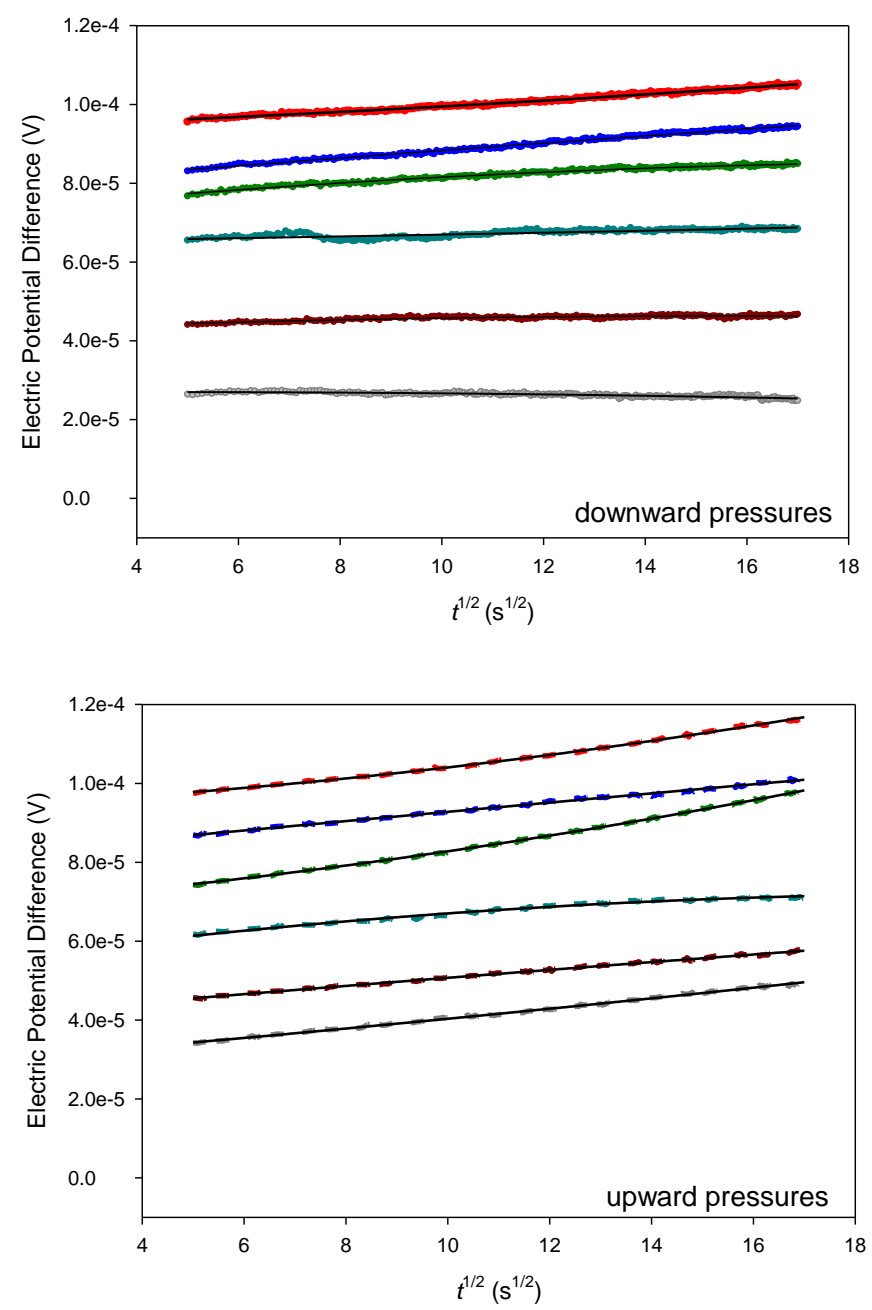

Fig. 4. Corresponding lines showing the electric potential difference $v s$. time square root for AMX membrane in downward (up) and upward (bottom) sequences. 
Figure 5 shows the values of the streaming potential $\Delta \psi_{0}$ obtained using short time interval (short $t$ ), as a function of the pressure difference applied to the membrane systems in the two measurement sequences, with the exception of membrane RXA with the upward pressure sequence. We found that there was a linear relationship between the streaming potential and the pressure difference across the membrane. Thus, the pressure coefficient $\beta_{0}$ was estimated from Eq. (3). Equation (5) allowed us to estimate the true pressure coefficient for the membranes in the downward and upward pressure sequences. These results are plotted in Figure 6, with the exception of the upward pressure sequence of the RXA membrane.
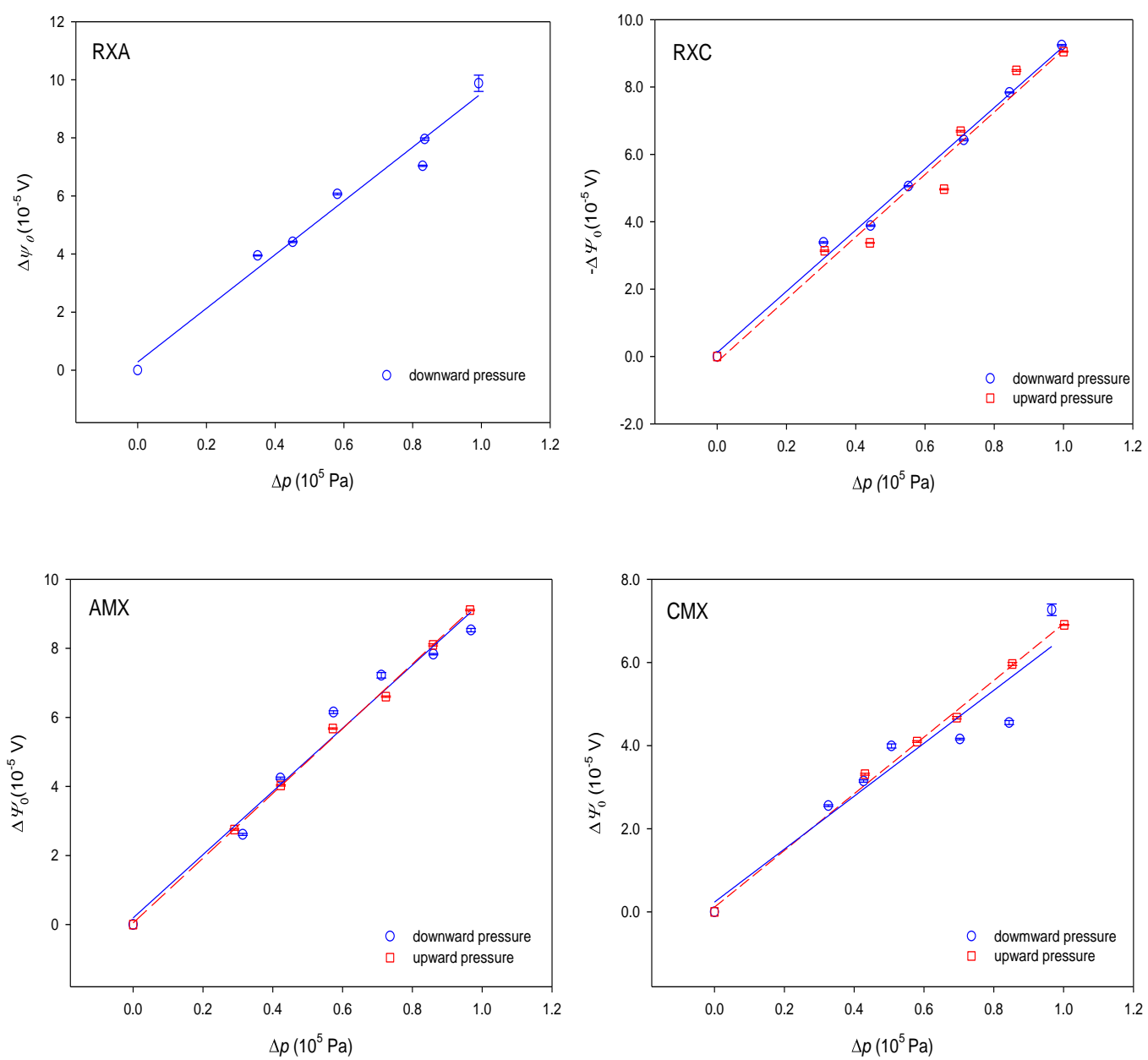

Fig. 5. Time variation of the streaming potential at zero time, $\Delta \psi_{0}$, as function of the pressure difference across the membrane. 


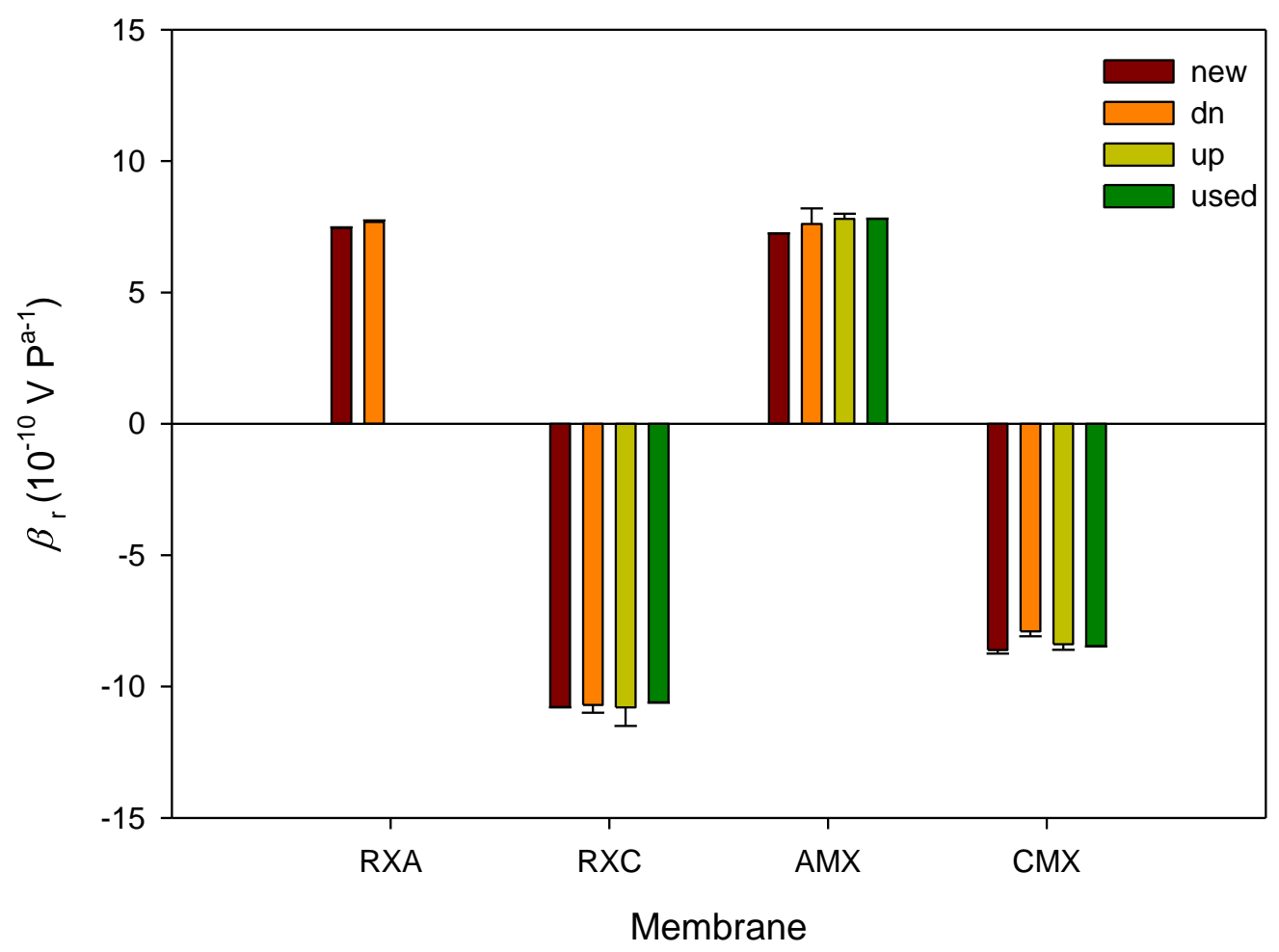

Fig. 6. Pressure coefficients estimated for new and used membranes, in the downward and upward pressure sequences.

We found that, with the exception of the RXA membrane, the differences between the values of $\beta_{r}$ (shown in Table 2), $\beta_{r}{ }^{d w}$, and $\beta_{r}{ }^{u p}$ were within the experimental error. This fact may indicate that no hysteresis was present in the determination of the pressure coefficient, and that the measurement process did not affect to the surface charge properties of the membrane.

Figure 7 shows the values of $L_{\mathrm{p}}$ obtained, using Eq. (9) for each applied pressure difference. As can be observed, the influence of the transmembrane pressure on the hydraulic permeability seems, in general, larger at low-pressure differences. In addition, the values of $L_{p}$ estimated in the transitory interval were, in general, higher than the corresponding stationary values. To analyse the relevance of this fact, we performed a one-sample t-test with each measurement series, downward and upward pressure in 
transitory and stationary intervals. The analysis showed that the transmembrane pressure value had a significant influence in all cases, with the exception of homogeneous membranes for stationary values in the downward pressure mode. One way ANOVA study was performed to analyze the influence of the measurement method. No significant influence was found for cationic membranes. In contrast, a significant influence was found with anionic AMX membrane between transitory and stationary values measured with downward pressure sequence. In addition, significant differences were only obtained in the downward pressure sequence when heterogeneous membranes are considered. Anionic RXA membrane seems to be strongly affected by the measurement process. For this membrane, the time-dependent building of the electric potential was lower than for the other membranes, as well as the relaxation time after the pressure difference suppression. Some authors have related the mechanical relaxation with time to the different types of polymer chains constituting the membrane matrix [71]. In addition, the relaxation times becomes longer, the longer and more flexible the polymer chains in the liquid phase. The results could indicate that the downward pressure sequence makes the membrane polymeric matrix more flexible. The values of $L_{\mathrm{p}}$ obtained by using Eq. (8) were two orders of magnitude higher than in the upward pressure sequence, and differences were only observed between transitory and stationary values in the downward pressure sequence. It would indicate that a given transmembrane pressure strongly affects the membrane matrix in a non-reversible way, but also that Eq. (8) could be not applicable in this case to estimate the volume flow through the membrane. Further work is necessary to analyse the origin of this behaviour.

To quantify the effect of the measured process in the analysed parameters, pressure coefficient and hydraulic permeability were estimated from the data obtained with the used membrane samples for the last applied transmembrane pressure difference (around 
1 bar). The results are shown in Table 3. With the exception of anionic Ralex membrane, no significant difference was observed in the pressure coefficient, obtaining similar values within the experimental errors. On the contrary, the measurement process seems to affect the hydraulic permeability of the membranes, mainly for RXA membrane, which increased this value in three magnitude orders with respect to the value obtained for the new unused membrane sample. The mechanical properties of this membrane seem to be strongly affected by the applied transmembrane pressure.
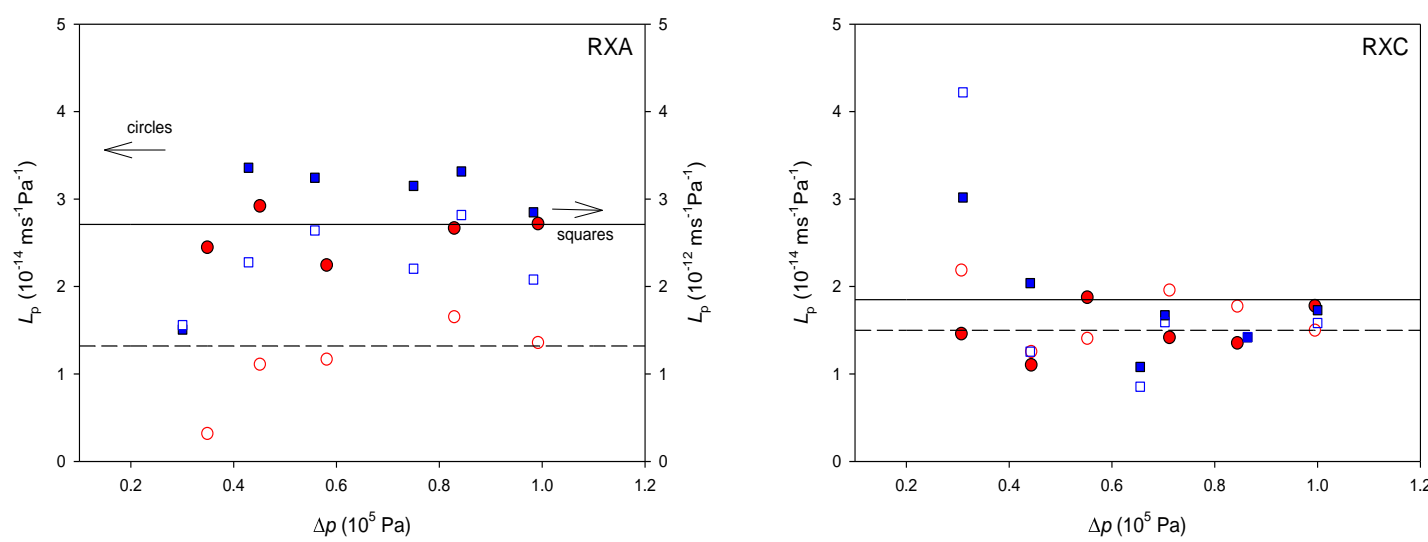

\begin{tabular}{|cl|}
\hline O & Transient, downward pressure \\
0 & Stationary, downward pressure \\
$\mathbf{\square}$ & Transient, upward pressure \\
$\square$ & Stationary, upward pressure \\
\hline- & Transient, new sample \\
\hline-- & Stationary, new sample
\end{tabular}
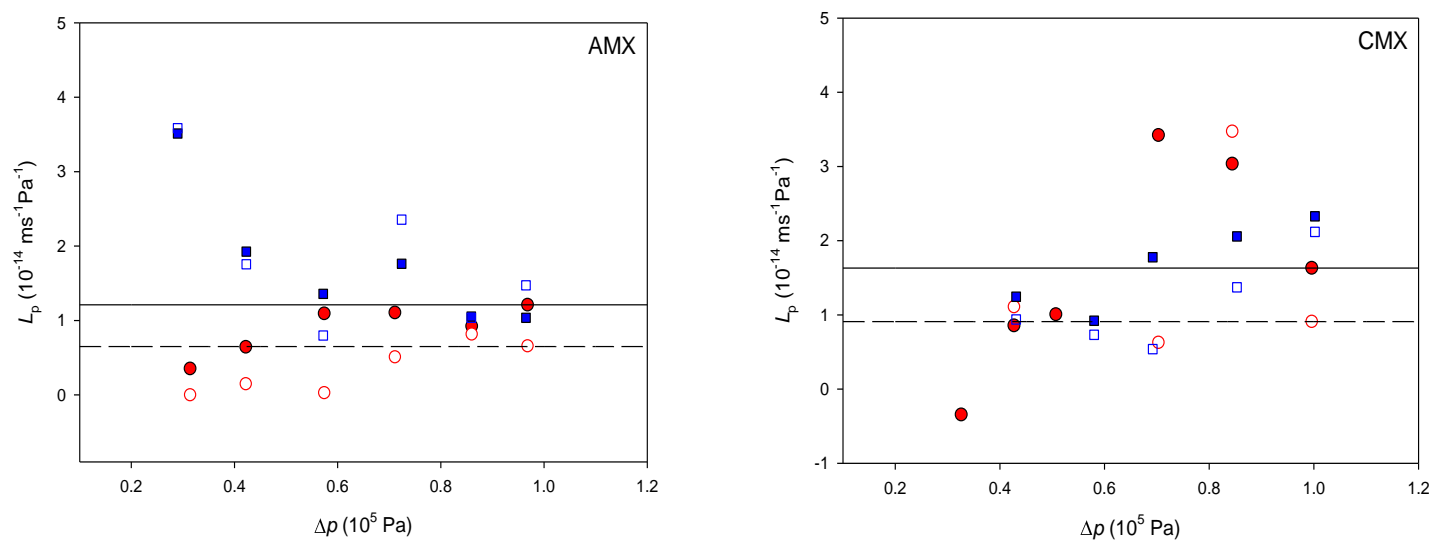

Fig. 7. Hydraulic permeability, $L_{p}$, as a function of the pressure difference across the membrane. Continuous and dotted lines indicate the values of $L_{\mathrm{p}}$ obtained with new samples at the highest applied transmembrane pressure. 


\section{Table 3}

Pressure coefficient, electro-osmotic drag coefficient, and hydraulic permeability, estimated from transient and stationary regimes, with used membrane samples at the highest pressure.

\begin{tabular}{|l|c|c|c|c|c|}
\hline Membrane & $\begin{array}{c}\boldsymbol{\Delta} \boldsymbol{p} \\
\left(10^{5} \mathrm{~Pa}\right)\end{array}$ & $\begin{array}{c}\boldsymbol{\beta}_{\boldsymbol{r}} \text {, used } \\
\left(10^{-10} \mathrm{~V} \mathrm{~Pa}^{-1}\right)\end{array}$ & $\boldsymbol{k}_{\boldsymbol{w} \text {, used }}$ & $\begin{array}{c}\boldsymbol{L}_{\mathbf{p}}{ }^{\text {tran }} \\
\left(10^{-14} \mathrm{~ms}^{-1} \mathrm{~Pa}^{-1}\right)\end{array}$ & $\begin{array}{c}\boldsymbol{L}_{\mathbf{p}} \text { stat } \\
\left(10^{-14} \mathrm{~ms}^{-1} \mathrm{~Pa}^{-1}\right)\end{array}$ \\
\hline RXA & 0.982 & ---- & --- & $274 \pm 1$ & $185 \pm 1$ \\
\hline RXC & 1.000 & $-10.60 \pm 0.02$ & 6 & $1.73 \pm 0.02$ & $1.58 \pm 0.02$ \\
\hline AMX & 0.965 & $7.86 \pm 0.01$ & 4 & $1.00 \pm 0.02$ & $1.42 \pm 0.02$ \\
\hline CMX & 1.002 & $-8.46 \pm 0.02$ & 5 & $2.33 \pm 0.07$ & $2.12 \pm 0.07$ \\
\hline
\end{tabular}

\subsection{Determination of zeta potential and intrinsic permeability.}

Zeta potential, $\zeta$, has been estimated from the measured pressure coefficient using Eq. (7). The values obtained in the present study for the different membrane systems are shown in Table 4.

\section{Table 4}

Zeta potential, $\zeta$, and intrinsic permeability, $K$, estimated for new and used membrane samples.

\begin{tabular}{|l|c|c|c|c|c|c|}
\hline Membrane & $\begin{array}{c}\zeta_{\text {,new }} \\
\left(10^{-3} \mathrm{~V}\right)\end{array}$ & $\begin{array}{c}\boldsymbol{\zeta}_{\text {,used }} \\
\left(10^{-3} \mathrm{~V}\right)\end{array}$ & $\begin{array}{c}\boldsymbol{K}_{\text {new }}^{\text {tran }} \\
\left(10^{-20} \mathrm{~m}^{2}\right)\end{array}$ & $\begin{array}{c}\boldsymbol{K}_{\text {new }}^{\text {stat }} \\
\left(10^{-20} \mathrm{~m}^{2}\right)\end{array}$ & $\begin{array}{c}\boldsymbol{K}_{\text {used }}^{\text {tran }} \\
\left(10^{-20} \mathrm{~m}^{2}\right)\end{array}$ & $\begin{array}{c}\boldsymbol{K}_{\text {used }}^{\text {stat }} \\
\left(10^{-20} \mathrm{~m}^{2}\right)\end{array}$ \\
\hline RXA & 11 & --- & 1.76 & 0.88 & 184 & 134 \\
\hline RXC & -15.3 & -15.1 & 1.2 & 0.98 & 1.1 & 1.0 \\
\hline AMX & 10.3 & 11.2 & 0.145 & 0.080 & 0.13 & 0.18 \\
\hline CMX & -12.2 & -12.0 & 0.25 & 0.14 & 0.36 & 0.33 \\
\hline
\end{tabular}

Similar values were obtained, within the experimental error, with new samples under the same experimental conditions. For used membrane samples, the results depended on the membrane history, but a similar result was obtained, within the experimental error, when a measured was repeated applying the same transmembrane pressure to the same sample.

These results were in agreement with values existing in the literature for similar membrane systems $[7,11,72]$. As can be observed, when membranes with equal 
selective character are compared, Zeta potential was higher at higher IEC values, in agreement with results found in the literature [7] with sulfonated cation-exchange membranes.

The intrinsic permeability, $K$, can be estimated for each membrane from the corresponding $L_{\mathrm{p}}$ value obtained at the highest pressure (around 1 bar) and Eq. (11). The results are also shown in Table 4. As can be observed, with the exception of the used Ralex RXA membrane, the intrinsic permeability values were in the nano Darcy range, and they were higher for heterogeneous membranes, with lower density. In the hardsphere approximation, the pressure derivative of the mean free path is isothermal compressibility multiplied by mean free path, which is approximately -11 femtometers per bar, so we expect the Knudsen number to be practically constant, and the variation with pressure is therefore not explained by rarefaction effects [73].

Higher values for $K$ were observed in the transitory interval, probably due to the transmembrane pressure application make the membrane more compact as it reaches stationary interval. The high values observed for Ralex RXA membrane with the used membrane sample seems to indicate that the transmembrane pressure application strongly affects the membrane structure, and the application of a transmembrane pressure produces an irreversible change in it. In contrast, this effect was not observed in the Ralex RXC cation membrane, even though they have similar matrix composition. However, a close inspection of images in Figure 1a reveals some differences in the structure of both heterogeneous membranes. Anionic Ralex membrane, with larger density, presents a higher difference between the values of $K$ obtained in transitory and stationary regimes, indicating the porosity of this membrane was more affected by the applied pressure difference. 
As it was previously commented, the behaviour observed may be related to the fact that the applied pressure affects the elastic membrane properties. Also, it seems that the time in building the electric potential, after the applied transmembrane pressure, is expanded, without any effect over the membrane surface charge properties. In addition, it can be speculated that the selective character of the membrane may play an important role in the observed behaviour. This is important because Eq. (8) assumes that the time dependence of the stablished potential difference is due to the contribution of the concentration polarization. Nevertheless, further work is necessary to understand the observations reported.

\section{Conclusions}

The influence of the application of a transmembrane hydraulic pressure over different charged polymeric membranes both on the streaming potential and on the hydraulic permeability has been studied.

Zeta potential value was estimated from the corresponding linear behaviour of the streaming potential as a function of the applied pressure difference. Regardless if new unused or used membrane samples were employed in the experiments, or increasingdecreasing pressure sequence was used, the results indicated that the measurements process does not cause permanent changes in the surface charge distribution of the polymeric membranes. It indicates that a sequential application of a pressure gradient over a same membrane sample does not alter its zeta potential. Values of zeta potentials in the range of $10^{-2} \mathrm{~V}$ were obtained. On the contrary, the hydraulic permeability changed with the transmembrane pressure, probably due to dimensional changes in the membrane samples originated in the experiments, indicating a possible irreversible change in the polymeric membrane. The intrinsic permeability of the investigated 
membranes was in the nano Darcy range, and it was higher for heterogeneous membranes, with lower density. In this case, new samples should be used to estimate the true intrinsic permeability from transversal streaming potential measurements.

\section{Declaration of competing interest}

The authors declare that they have no known competing financial interests or personal relationships that could have appeared to influence the work reported in this paper.

\section{Acknowledgments}

Financial support of this work by Banco de Santander and Universidad Complutense de Madrid within the framework of Project PR75/18-21589 is gratefully acknowledged.

\section{CRediT authorship contribution statement}

V.M. Barragán: Conceptualization, Methodology, Validation, Formal Analysis, Investigation, Resources, Writing-Original Draft, Writing-Review \& Editing, Visualization, Project Administration, Funding acquisition, Supervision.

J. P. G. Villaluenga: Validation, Formal Analysis, Writing-Review \& Editing. M.A. Izquierdo-Gil: Formal Analysis, Writing-Review \& Editing.

K.R. Kristiansen: Methodology, Formal Analysis, Writing-Review \& Editing.

\section{References}

[1] F. Helfferich, Ion Exchange, Dover Publications, INC., New York, 1995.

[2] M. J. Ariza, J. Benavente, Streaming potential along the surface of polysulfone membranes: a comparative study between two different experimental systems and 
determination of electrokinetic and absorption parameters, J. Membr. Sci. 190 (2001) 119-132.

[3] N. D. Lawrence, J. M. Perera, M. Iyer, M. W. Hickey, G. W. Stevens, The use of streaming potential measurements to study the fouling and cleaning of ultrafiltration membranes, Sep. Purif. Technol. 48 (2006) 106-112.

[4] D. J. Johnson, D. L. Oatley-Radcliffe, N. Hilal, State of the art review on membrane surface characterization: Visualisation, verification and quantification on membrane properties, Desalination 434 (2018) 12-36.

[5] V. M. Barragán, C. Ruiz-Bauzá, J. L. Imaña, Streaming potential across cationexchange membranes in methanol-water electrolyte solutions, J. Colloid Interface Sci. 294 (2006) 473-481.

[6] A. Fiumefreddo, M. Utz, Bulk streaming potential in poly(acrylic acid)/poly(acrylamide) hydrogels, Macromolecules 43 (2010) 5814-5819.

[7] H. Xie, T. Saito, M. A. Hickner, Zeta potential of ion-conductive membranes by streaming current measurements, Langmuir 27 (2011) 4721-4727.

[8] D. T. Luong, R. Sprik, Streaming potential and electroosmosis measurements to characterize porous materials, ISRN Geophys. 213 (2011) 496352.

[9] R. Saini, A. Garg, D. P.J. Barz, Streaming potential revisited: The influence of convection on the surface conductivity, Langmuir 30 (2014) 10950-10961.

[10] P. Somovilla, J. P. G. Villaluenga, V. M. Barragán, M. A. Izquierdo-Gil, Experimental determination of the streaming potential across cation-exchange membranes with different morphologies, J. Membr. Sci. 500 (2016) 16-24.

[11] B. D. Coday, T. Luxbacher, A. E. Childress, N. Almaraz, P. Xu, T. Y. Cath, Indirect determination of zeta potential at high ionic strength: specific application to semipermeable polymeric membranes, J. Membr. Sci. 478 (2015) 58-64. 
[12] S. Cheng, M. Fu, F. A. Kulacki, Characterization of a porous transducer using a capillary bundle model: permeability and streaming potential prediction, Int. J. Heat Mass Tran. 118 (2018) 349-354.

[13] S. Datta, A. T. Conlisk, D. M. Kanani, A. L. Zydney, W. H. -Fissell, S. Roy, Characterizing the surface charge of synthetic nanomembranes by the streaming potential method, J. Colloid Interface Sci. 348 (2019) 85-95.

[14] J. Zeng, H. Ye, H. Liu, H. Xie, Electrokinetic characterization of the A12O3 MF membrane by streaming potential measurements. Desalination 235 (2009) 102-109.

[15] H. Rho, K. Chon, J. Cho, Surface charge characterization of nanofiltration membranes by potentiometric titrations and electrophoresis: Functionality vs. zeta potential. Desalination 4271 (2018) 19-26.

[16] X. Wei, X. Kong, C. Sun, J. Chen, Characterization and application of a thin-film composite nanofiltration hollow fiber membrane for dye desalination and concentration Chem. Eng. J. 223 (2013) 172-182

[17] J.-H. Cheng, T.-S. Chung, Self-sharpening phenomenon arisen by ion-exchange membranes in multi-compartment free-flow isoelectric focusing (IEM-FFIEF), Chem. Eng. Sci. 64 (2009) 5222-5230.

[18] Y. Zhao, J. Zhu, J. Ding, B. Van der Bruggen, J. Shen, C. Gao, Electric-pulse layerby-layer assembled of anion Exchange membrane with enhanced monovalent selectivity, J. Membr. Sci. 548 (2018) 81-90.

[19] A. Campione, L. Gurreri, M. Ciofalo, G. Micale, A. Tamburini, A. Cipollina, Electrodialysis for water desalination: A critical assessment of recent developments on process fundamentals, models and applications, Desalination 434 (2018) 121-160. 
[20] A. E. Childress, M. Elimelech, Effect of solution chemistry on the surface charge of polymeric reverse osmosis and nanofiltration membranes, J. Membr. Sci. 1996, 119, 253-268.

[21] A. S. A-Almoudi, Factors affecting natural organic matter (NOM) and scaling fouling in NF membranes: a review, Desalination 259 (2010)-1-10.

[22] A. Imbrogno A. Tiraberri, S. Abbenante, S. Weyand, R. Schwaiger, T. Luxbacher, A. I. Shäfer, Organic fouling control through magnetic ion exchange-nanofiltration (MIEX-NF) in water treatment, J. Membr. Sci. 549 (2018) 474-485.

[23] D. A. Vermaas, D. Kunteng, M. Saakes, K. Nijmeijer, Fouling in reverse electrodialysis under natural conditions, Water Res. 47 (2013) 1289-1298.

[24] N. Li, J. Zhang, Y. Tian, J. Zhao, J. Zhang, W. Zuo, Anti-fouling potential evaluation of PVDF membranes modified with $\mathrm{ZnO}$ against polysaccharide, Chem. Eng. J. 304 (2016) 165-174.

[25] M.A. Al Mamun, M. Sadrzadeh, R. Chatterjee, S. Bhattacharjee, S. De, Colloidal fouling of nanofiltration membranes: A novel transient electrokinetic model and experimental study, Chem. Eng. Sci. 138 (2015) 153-163

[26] X. Wei, X. Kong, C. Sun, J. Chen, Characterization and application of a thin-film composite nanofiltration hollow fiber membrane for dye desalination and concentration, Chem. Eng. J. 223 (2013) 172-182.

[27] V. Titorova, K. Sabbatouskiy, V. Sarapulova, E. Kirichenko, V. Sobolev, K. Kirichenko, Characterization of MK-40 membrane modified by layers of cationexchange and anion exchange polyelectrolytes, Membranes 10 (2020) 20.

[28] J. Liu, J. Xiong, X. Ju, B. Gao, L. Wang, M. Sillanpää, Streaming potential for identification of foulants absorption on PVDF membrane surface, J. Membr. Sci. 566 (2018) 428-434. 
[29] P. Ortiz-Albo, R. Ibañez, A. Urtiaga, I. Ortiz, Phenomenological prediction of desalination brines nanofiltration through the indirect determination of zeta potential, Sep. Purif. Technol. 210 (2019) 746-753.

[30] S. Byun, J-H Kwon, M-H. Kim, K-Y. Park, S. Lee, Automatic control of polymer dosage using streaming potential for waterworks sludge conditioning, Sep. Purif. Technol. 57 (2007) 230-236.

[31] Y. A. Boussouga, A. Lhassani, Study of mass transfer mechanisms for reverse osmosis and nanofiltration membranes intended for desalination, JMES 8 (2017) 11281138.

[32] M.M. Al-Doury, A discussion about hydraulic permeability and permeability, Pet. Sci. Technol. 28 (2010) 1740-1749.

[33] A. M. dos Santos, A. C. Harbert, H. C. Ferranz, Polyethermirimide/polyvinyloyrrolidone hollow-fiber membranes for use in hemodialysis, Braz. J. Chem. Eng. 36 (2019) 1645-1652.

[34] J.P.G. Villaluenga, B. Seoane, V. M. Barragán, C. Ruiz-Bauzá, Permeation of electrolyte water-methanol solutions through a Nafion membrane, J. Colloid Interface Sci. 268 (2003) 476-481.

[35] S. Chen, X. Zhang, H. Liu, Effect of pressure difference between adjacent channels in an adjustable flow field in PEM fuel cells, Int. J. Hydrogen Energ. 42 (2017) 46674672.

[36] S. Pawlowski J. G. Crespo, S. Velizarov, Pressure drop in reverse electrodialysis: Experimental and modeling studies for stacks with variable number of cell pairs, J. Membr. Sci. 462 (2014) 96-111.

[37] Y. Jiao, C. Yang, Y. Kang, Energy conversion from salinity gradients by forward osmosis-electrokinetics, J. Phys. Chem. C 118 (2014) 10574-10583. 
[38] A. Mansouri, S. Bhattacharjee, L. W. Kostiuk, Electrokinetic energy conversion by microchannel array: electrical analogy, experiments, and electrode polarization, J. Phys. Chem. C 118 (2014) 24310-24324.

[39] A. Bentien, T. Okada, S. Kjelstrup, Evaluation of nanoporous polymer membranes for electrokinetic energy conversion in power applications, J. Phys. Chem. C, 117 (2013) $1582-1588$.

[40] D. L. Oatley-Radcliffe, N. Aljohani, P. M. Williams, N. Hilal, Elkectrokinetic Phenomena for Membrane Charge, in N. Hilal, A. F. Ismail, T. Tatsuura, D. OatleyRadcliffe (Eds.): Membrane Characterization, Elsevier, 2017, Chap. 18.

[41] J. D. Badia, O. Gil-Castell, A. Ribes-Greus, Long-term properties and end-of-life of polymers from reversible resources, Polym. Degrad. Stab. 137 (2017) 35-37.

[42] S. V. Venkatesan, E. Kjeang, Effects of isolated chemical and mechanical degradation stressors on the ionomer morphology in fuel cell membranes, Polym. Degrad. Stab. 146 (2017) 132-139.

[43] G. Blandin, H. Vervoort, A. D’Haese, K. Shoutteten, J.V. Busshe, L. Vanhaecke, D. T. Myat, P. Le-Clech, A. R. D. Verliefde, Impact of hydraulic pressure on membrane deformation and trace organic contaminants rejection in pressure assisted osmosis (PAO), Process Saf. Environ. 102 (2016) 316-327.

[44] L. Zich, N. Václavíková, Characterization of ion exchange material behavior under pressure simulating electro-membrane cell conditions, Period. Polytech-Chem. 62 (2018) 150-155.

[45] V. M. Barragán, E. Pastuschuk, Viscoelastic deformation of sulfonated polymeric cation-exchange membranes exposed to a pressure gradient, Mater. Chem. Phys. 146 (2014) 65-72. 
[46] G. Battaglia, L. Gurreri, G. A. Farulla, A. Cipollina, A. Pirrota, G. Micale, M. Ciofalo, Membrane Deformation and its effects on flow and mass transfer in the electromembrane processes, Int. J. Mol. Sci. 20 (2019) 1840.

[47] S. Kjelstrup, D. Bedeaux, Non-Equilibrium Thermodynamics of Heterogeneous Systems, World Scientific, New Jersey, 2008.

[48] K.S. Førland, T. Førland, S. Kjelstrup Ratkje, Irreversible thermodynamics theory and applications, John Wiley and Sons, Chichester, 1998.

[49] K. S. Splieger, On the measurement of streaming potential with silver-silver chloride electrodes, Desalination 15 (1974) 135-140.

[50] T. Yamanaka, T. Takeguchi, H. Takahashi, W. Ueda, Water transport during ion conduction in anion-exchange and cation-exchange membranes, J. Electrochem. Soc. 156 (2009) 13831-13835.

[51] R. P. Rastogi, R. C. Srivastava, S. N. Singh, Nonequilibrium thermodynamics of electrokinetic phenomena, Chem. Rev. 93 (1993) 1945-1989.

[52] M. Elimelech, W. H. Chen, J. J. Waypa, Measuring the zeta (electrokinetic) potential of reverse osmosis membranes by a streaming potential analyser, Desalination 95 (1994) 269-286.

[53] T. Okada, S. K. Ratkje, H. Hanche-Olsen, Water transport in cation exchange membranes, J. Membr. Sci. 66 (1992) 179-192.

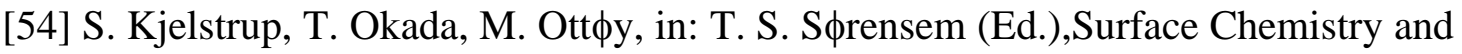
Electrochemistry of Membranes, Dekker, New York, 1990, Chap. 13.

[55] A. K. Datta, Hydraulic permeability of food tissues, Int. J. Food Prop. 9 (2006) $767-780$

[56] M. M. I. Al-Doury, A discussion about hydraulic permeability and permeability, Pet. Sci. Technol. 28 (2010) 1740-1749. 
[57] H. Strathmann, Ion-Exchange membrane separation processes. In: Membrane science and technology series. Amsterdam: Elsevier, 2004.

[58] J. Benavente, G. Jonsson, A comparison between streaming potential and membrane potential measured across single charged and bipolar membranes, Sep. Purif. Technol. 22-23 (2001) 637-642.

[59] J. M. Reynard, L. Larchet, G. Bulvestre, B. Auclair, Determination of the streaming potential in ion-exchange membranes, J. Membr. Sci. 67 (1992) 57-66.

[60] M. Pluta, M. Murariu, M. Alexandre, A. Galeski, P. Dubois, Polylactide compositions. The influence of ageing on the structure, thermal and viscoelastic properties of PLA/calcium sulfate composite, Polym. Degrad. Stab. 93 (2008) 925-931. [61] X. Wang, J. P. McClure, P. S. Fedkiw, Transport properties of proton- and hydroxide-exchange membranes for fuel cells, Electrochim. Acta 79 (2012) 126-132. [62] L. C. Jacobson, X. Ren, V. Molinero, Assessing the effects of crowding pore size, and interactions on electro-osmotic drag coefficients, J. Phys. Chem. C 118 (2014) $7513-7520$

[63] D. García-Nieto, V. M. Barragán, A comparative study of the electro-osmotic behavior of cation and anion exchange membranes in alcohol-water media, Electrochim. Acta 154 (2015) 166-176.

[64] M. Ise, K. D. Kreuer, J. Maier, Electroosmotic drag in polymer electrolyte membranes: an electrophoretic NMR study, Solid State Ionics 125 (1999) 213-223. [65] X. Ren. W. Henderson, S. Gottesfeld, Electro-osmotic drag of water in ionomeric membranes, New measurements employing a direct methanol fuel cell, J. Electrochem. Soc. 144 (1997) L267-L270. 
[66] T. Shaffer, T. Tschinder, V. Hacker, J. O. Besenhard, Determination of methanol diffusion and electroosmotic drag coefficients in proton-exchange-membranes for DMFC, J. Power Sour. 153 (2006) 210-216.

[67] J. O’M. Brockris, A. K. N. Reddy, Modern Electrochemistry, Vol. 1. Plenum Press, New York, 1970.

[68] S. Koter, W. Kujawski, I. Koter, Importance of the cross-effects in the transport through ion-exchange membranes, J. Membr. Sci. 301 (2007) 93-106.

[69] V. M. Barragán, S. Muñoz, Influence of a microwave irradiation on the swelling and permeation properties of a Nafion membrane, J. Membr. Sep. Technol. 4 (2015) 3239.

[70] L. Zich and N. Václavíková, Characterization of ion exchange material behaviour under pressure simulating electro-membrane cell conditions, Period. Polytech-Chem. 62 (2) 2018 150-155.

[71] R. P. Rastogi, C. R. Srivastava, Nonequilibrium thermodyamics of electrokinetic phenomena, Chem. Rev. 93 (1993) 1945-1990.

[72] K. J. Kim, A. G. Fane, M. Nyustrom, A. Pihlajamaki, W. R. Bowen, Evaluation of electroosmosis and streaming potential for measurement of electric charges of polymeric membranes, J. Membr. Sci. 116 (1996) 149-159.

[73] S. Colin, Rarefaction and compressibility effect on steady and transient gas flows in microchannels, Microfluid Nanofluid 1 (2005) 268-279. 